\title{
Effect of mechanical aortic valve orientation on coronary artery flow: Comparison of tilting disc versus bileaflet prostheses in pigs
}

\author{
Peter Kleine, $M D^{\mathrm{a}}$ \\ Mirella Scherer, MD \\ Ulf Abdel-Rahman, $M D^{a}$ \\ Armin A. Klesius, MD \\ Hans Ackermann, $\mathrm{PhD}^{\mathrm{b}}$ \\ Anton Moritz, MD ${ }^{\mathrm{a}}$
}

\footnotetext{
From the Department of Thoracic \& Cardiovascular Surgery a and the Department of Biomedical Statistics, ${ }^{\text {b }}$ Johann-WolfgangGoethe University, Frankfurt/Main, Germany

Study funding by: Medtronic Inc, Minneapolis, Minn.

Received for publication April 16, 2002; revisions requested April 24, 2002; revisions received April 26, 2002; accepted for publication April 27, 2002.

Address for reprints: Peter Kleine, MD, Department of Thoracic \& Cardiovascular Surgery, University Hospital, TheodorStern-Kai 7, 60596 Frankfurt/Main, Germany (E-mail: P.Kleine@em.uni-frankfurt.de).

J Thorac Cardiovasc Surg 2002;124:925-32

Copyright $(\odot) 2002$ by The American Association for Thoracic Surgery

0022-5223/2002 \$35.00+0 $\quad \mathbf{1 2 / 1 / 1 2 6 0 4 6}$

doi: $10.1067 / \mathrm{mtc} .2002 .126046$
}

Objective: Orientation for optimal systolic performance of tilting disc and bileaflet aortic valves was defined in previous studies. The present study investigates the influence of valve orientation on coronary artery flow in an animal model.

Methods: A rotation device holding either a Medtronic Hall tilting disc $(\mathrm{n}=4$; Medtronic, Inc, Minneapolis, Minn), a St Jude Medical bileaflet $(\mathrm{n}=4$; St Jude Medical, Inc, St Paul, Minn), or a Medtronic Advantage bileaflet $(\mathrm{n}=3)$ aortic valve was implanted. The device allowed rotation of the valve without reopening the aorta. Flow through the left anterior descending coronary artery was measured preoperatively and at normal versus high cardiac output after weaning from extracorporeal circulation. Measurements were performed at the best and worst hemodynamic position, as defined previously.

Results: Coronary flow rates were similar in all animals preoperatively $(26 \pm 4.1$ $\mathrm{mL} / \mathrm{min}$ ). After aortic valve replacement, left anterior descending flow increased significantly to $58.2 \pm 10.6 \mathrm{~mL} / \mathrm{min}$. Highest flow rates at normal cardiac output were found in the optimum orientation, especially for the Medtronic valves (Medtronic Hall, $64 \pm 8.7 \mathrm{~mL} / \mathrm{min}$; Medtronic Advantage, $64.6 \pm 11.6 \mathrm{~mL} / \mathrm{min}$; St Jude Medical, $48.3 \pm 10.3 \mathrm{~mL} / \mathrm{min}$ ), whereas the worst position demonstrated significantly lower left anterior descending flow, with no differences among valves (Medtronic Hall, $37.5 \pm 1.3 \mathrm{~mL} / \mathrm{min}$; St Jude Medical, $35.7 \pm 10.7 \mathrm{~mL} / \mathrm{min}$; Medtronic Advantage, $39.8 \pm 10 \mathrm{~mL} / \mathrm{min}$ ). Left anterior descending artery flow increased significantly with higher cardiac output.

Conclusions: Coronary blood flow was significantly influenced by mechanical aortic valve implantation and the orientation of prostheses. For both valve designs, the previously defined optimum orientation with respect to pressure gradients and turbulence demonstrated the highest left anterior descending flow rates. Even in its optimum orientation, the St Jude Medical valve showed significantly lower coronary flow than the other valves.

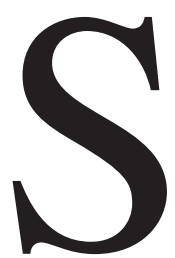

ystolic and diastolic performance of tilting disc and bileaflet mechanical aortic valve substitutes have been investigated intensively in vitro $^{1-3}$ and in vivo ${ }^{4-6}$ for the past 20 years. The in vitro studies usually did not incorporate the physiologic anatomy (angled outflow tract and sinuses of Valsalva), although these facts have an important effect on the flow conditions in the aortic root.7,8 Thus, in vivo studies reflect the complex reality, with a resulting asymmetric-eccentric flow and the highest flow velocities along the noncoronary cusp, ${ }^{9}$ more precisely than in vitro studies. 
Because of the flow profile in the aortic root, orientation of mechanical aortic valve substitutes has an important effect on the hemodynamic performance, and each valve design has its own optimal orientation. Animal studies must be performed in addition to in vitro setups to define this design-related optimal orientation. ${ }^{10}$ In a previous animal study, ${ }^{11}$ optimal orientation for tilting disc (Medtronic Hall [MH]; Medtronic, Inc, St Paul, Minn) and bileaflet (St Jude Medical [SJM]; St Jude Medical, Inc, St Paul, Minn) valves was investigated. The $\mathrm{MH}$ valve showed almost physiologic hemodynamic performance with respect to downstream turbulence, with its major orifice facing the right posterior wall, the region of the noncoronary (posterior) cusp. The SJM valve could not achieve the almost physiologic results of the MH valve but was less susceptible to orientation. Its best results were obtained with one orifice oriented toward the right cusp. In this orientation the area of major flow was distributed equally among the 2 side orifices and the central slit.

After this animal study, the systolic performance of both valves was investigated in clinical studies. ${ }^{12-14}$ The tilting disc mechanism showed superior hemodynamic performance compared with that of the bileaflet mechanism with implantation of both valves in their optimum orientation. The superiority of the tilting disc mechanism was more pronounced in the smaller valves. The effect of valve orientation on the diastolic performance of mechanical aortic valves has not yet been investigated in such detail. It has been assumed that valve closure is determined exclusively on the basis of design and the valve-closure mechanism. Closing reflux and leakage flow both combine to create disturbed flow in the sinuses of Valsalva. ${ }^{15,16}$ The acute physiologic effect of these changes in aortic root flow pattern on coronary flow has not been fully elucidated. In one pilot study ${ }^{17}$ it was demonstrated that flow velocities in the left anterior descending artery (LAD) increased significantly immediately after aortic valve replacement, but this study focused on the effect of cardioplegia and not on valve design or orientation. The present study investigates the effect of these factors on LAD flow immediately after mechanical aortic valve replacement in an animal model. It was hypothesized that a tilting disc valve demonstrating low systolic downstream turbulence at the level of the aortic root would allow a more physiologic diastolic coronary perfusion. Thus, it was assumed that valve orientation will not only influence systolic values but also coronary artery flow. A 21-mm MH tilting disc valve and a 23-mm SJM valve were chosen because these valve sizes offered equivalent pressure gradients in a previous study. ${ }^{12}$ Additionally, a newly designed bileaflet valve was investigated, a $23-\mathrm{mm}$ Medtronic Advantage (MA) valve. This valve was chosen because it has a larger central slit and a reduced leakage flow compared with that of the SJM bileaflet valve substitute.

\section{Methods}

The animal study was performed according to the guidelines for animal experiments in Germany. The study comprised 11 healthy pigs with a body weight of $67 \pm 5 \mathrm{~kg}$. General anesthesia was achieved by administering fentanyl $\left(1.5 \mu \mathrm{g} \cdot \mathrm{kg}^{-1} \cdot \mathrm{h}^{-1}\right)$ and propofol $\left(2 \mathrm{mg} / \mathrm{kg}\right.$ for initiation and $10 \mu \mathrm{g} \cdot \mathrm{kg}^{-1} \cdot \mathrm{h}^{-1}$ for maintenance). Monitoring included electrocardiography, blood pressure, central venous pressure, pulmonary artery pressure, and blood temperature. Pulmonary capillary wedge pressure and cardiac output (CO) were measured intermittently, as mentioned below.

A median sternotomy was carried out in the usual manner. Measurement of hemodynamic parameters (heart rate, central venous pressure, blood pressure, pulmonary artery pressure, $\mathrm{CO}$, and pulmonary capillary wedge pressure) was performed. In addition, the LAD flow rate before aortic valve replacement was measured with a perivascular ultrasound device (Transonic Flow-QC; Transonic Systems Inc, Ithaca, NY). The coronary artery was dissected in its middle segment, and a 2.5-mm flow probe (Transonic BF 2.5 $\mathrm{SB})$ was placed and left in place for the remainder of the operation, providing continuous qualitative and quantitative measurement of LAD flow. ${ }^{18,19}$ Starting from the qualitative flow curves, total coronary flow was calculated by integral. The values mentioned in the "Results" section represent the calculated total coronary flow results.

Extracorporeal circulation was established by means of cannulation of one carotid artery and a 2-stage venous catheter. After crossclamping of the aorta, $1000 \mathrm{~mL}$ of St Thomas' Hospital solution was administered into the aortic root to achieve cardiac arrest, followed by $500 \mathrm{~mL}$ every 20 minutes administered directly into the coronary ostia. Normothermia was maintained during extracorporeal circulation. After complete dissection of the ascending aorta, the native valve was excised, and one of the 3 rotation devices was implanted with 3 running 4-0 Prolene sutures (Ethicon, Inc, Somerville, NJ).

The rotation device containing the $\mathrm{MH}$ valve was implanted in 4 pigs, the SJM valve in 4 pigs, and the MA valve in the remaining 3 pigs. All valves were rotated alternately between the previously defined optimum and worst orientation with respect to systolic performance. Furthermore, each valve was alternately measured in the initial optimum and worst orientation to avoid the performance of measurements in the same succession.

\section{Construction of the Rotation Devices}

The rotation devices (Acutec, St Michael, Minn) were comparable with those used in previous experiments. ${ }^{11}$ They consisted of an outer conventional sewing ring and 2 inner rings, between which the rotation was performed with 2 monofilament lines. The 21-mm MH, 23-mm SJM, and 23-mm MA valves were fixed into the inner ring. After valve implantation, the 2 monofilament lines were passed through the aortic wall; pulling one monofilament line $2 \mathrm{~cm}$ led to a $45^{\circ}$ rotation of the implanted valve without reopening of the aorta. The implanted rotation device holding the MH valve is shown in Figure 1.

Optimum and worst position for the MH tilting disc valve ${ }^{11}$. The optimum orientation was defined as orientation of the large 


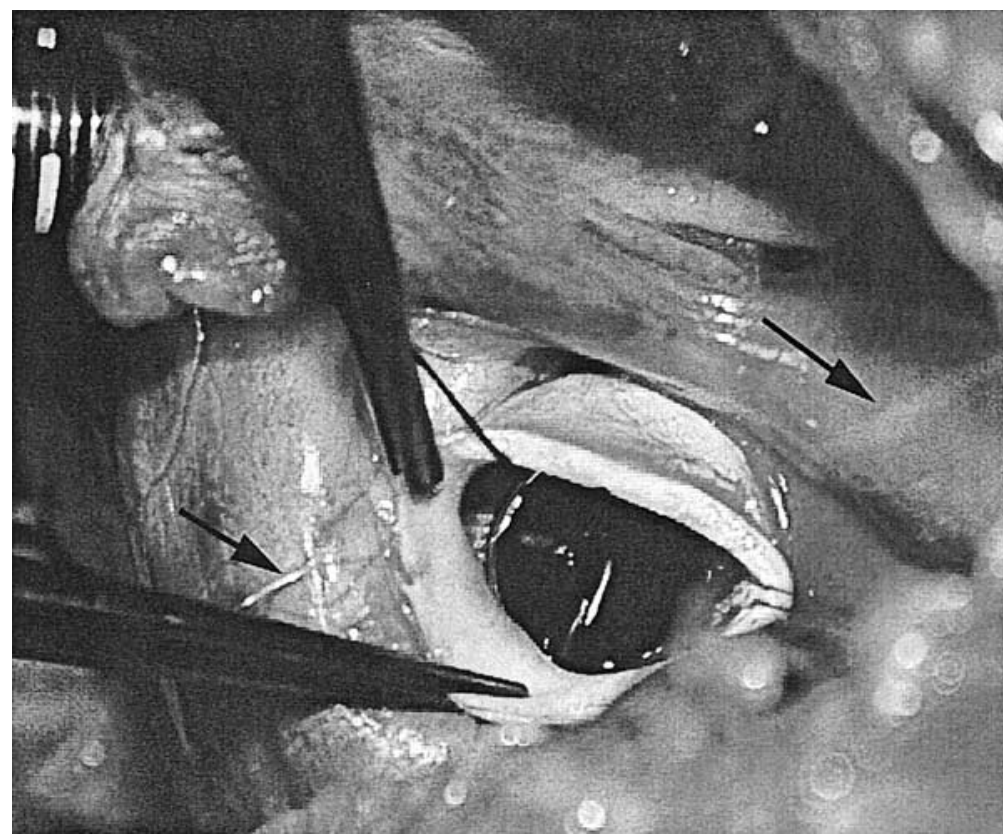

Figure 1. Implanted rotation device holding an MH tilting disc valve. Two monofilament lines (arrows) have been passed through the aortic wall. Pulling one of the lines $2 \mathrm{~cm}$ led to a $45^{\circ}$ rotation of the implanted valve.

opening toward the noncoronary cusp (Figure 2). ${ }^{12}$ A $180^{\circ}$ rotation of the implanted valve led to the worst orientation.

Optimum and worst position for the SJM bileaflet valve'11. In the optimum orientation one orifice faced the right coronary cusp (Figure 3). ${ }^{12}$ Rotation of $90^{\circ}$ led to the worst position.

Optimum and worst position for the MA bileaflet valve. The effect of orientation on the hemodynamic performance of this innovative valve has not yet been defined. Because of its design, it was assumed that this valve behaves similarly to the SJM bileaflet valve. Thus, the optimum and worst positions corresponded to those for the SJM valve.

The aortotomy was closed with 2 lines of running 4-0 Prolene sutures. Subsequent reperfusion resulted in a satisfactory hemodynamic situation. Thus, all pigs could be successfully weaned from extracorporeal circulation with no or low dosages of inotropic support.

After decannulation, a complete series of the above-mentioned hemodynamic parameters and the LAD flow rates were measured at a constant $\mathrm{CO}(4.2 \pm 0.4 \mathrm{~L} / \mathrm{min})$. The valves were then rotated into the opposite orientation. Again, the hemodynamic parameters and LAD flow rates were measured. The valves were repeatedly rotated between the different orientations to exclude the effect of time span between operation and measurements. $\mathrm{CO}$ was then increased to $5.9 \pm 0.3 \mathrm{~L} / \mathrm{min}$ with inotropic medication $(0.36-0.48$ $\mu \mathrm{g} \cdot \mathrm{kg}^{-1} \cdot \mathrm{min}^{-1}$ epinephrine) and administering additional intravenous volume. Hemodynamic parameters and LAD flow rates were again determined in both orientations.

\section{Statistical Analysis}

As a first step of statistical analysis, Gaussian normal distributions of results obtained for hemodynamic parameters and LAD flow rates were tested by using the Dallal-Wilkinson corrected and
Kolmogoroff-Smirnoff tests. ${ }^{20}$ If this could be verified as the result of a small deviation of results, differences between the valves were assessed with 2-sample $t$ tests, analysis of variance, and multiple comparisons with the Scheffé test with $95 \%$ confidence limits. ${ }^{20}$ The commercially available statistical software BIAS was used to perform the statistical analysis.

\section{Results}

The preoperative data did not vary significantly among animals. Heart rate was $95 \pm 7$ beats/min, and the other hemodynamic parameters were within normal ranges. The mean LAD flow rate was $25.9 \pm 3.2 \mathrm{~mL} / \mathrm{min}$, without differences among valve groups. The mean $\mathrm{CO}$ was $4.2 \pm$ $0.6 \mathrm{~L} / \mathrm{min}$. Aortic valve replacement could be performed without complications at a mean crossclamp time of $52 \pm 9$ minutes. Bypass time was $102 \pm 11$ minutes and did not show any significant differences among the 3 implanted valve groups. Figure 4 demonstrates the results of LAD coronary flow rate measurements in the different orientations postoperatively at normal and high COs. The results for normal $\mathrm{CO}$ were obtained at the following stable hemodynamic parameters. For MH valves, heart rate was $103 \pm$ 6 beats/min, systolic blood pressure was $100 \pm 9 \mathrm{~mm} \mathrm{Hg}$, diastolic blood pressure was $53 \pm 6 \mathrm{~mm} \mathrm{Hg}$, and $\mathrm{CO}$ was $4.1 \pm 0.4 \mathrm{~L} / \mathrm{min}$. For SJM valves, heart rate was $107 \pm 9$ beats/min, systolic blood pressure was $107 \pm 10 \mathrm{~mm} \mathrm{Hg}$, diastolic blood pressure was $58 \pm 8 \mathrm{~mm} \mathrm{Hg}$, and $\mathrm{CO}$ was $4.3 \pm 0.6 \mathrm{~L} / \mathrm{min}$. For MA valves, heart rate was $106 \pm 5$ beats/min, systolic blood pressure was $106 \pm 9 \mathrm{~mm} \mathrm{Hg}$, diastolic blood pressure was $55 \pm 6 \mathrm{~mm} \mathrm{Hg}$, and $\mathrm{CO}$ was 

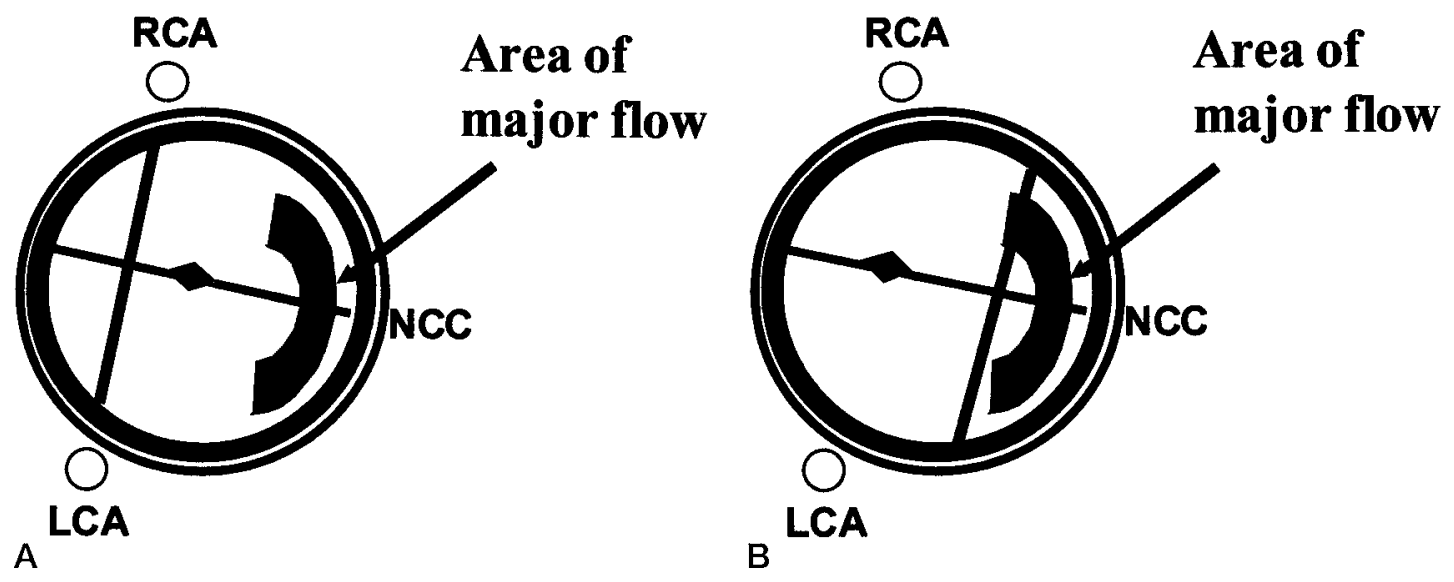

Figure 2. Optimum (A) and worst (B) orientation of the $M H$ tilting disc valve.12 In the hemodynamically best orientation, the major orifice faces the noncoronary cusp, the region of major flow during ejection. Rotation of $180^{\circ}$ leads to the hemodynamically worst orientation. RCA, Right coronary artery; NCC, noncoronary cusp; LCA, left coronary artery.
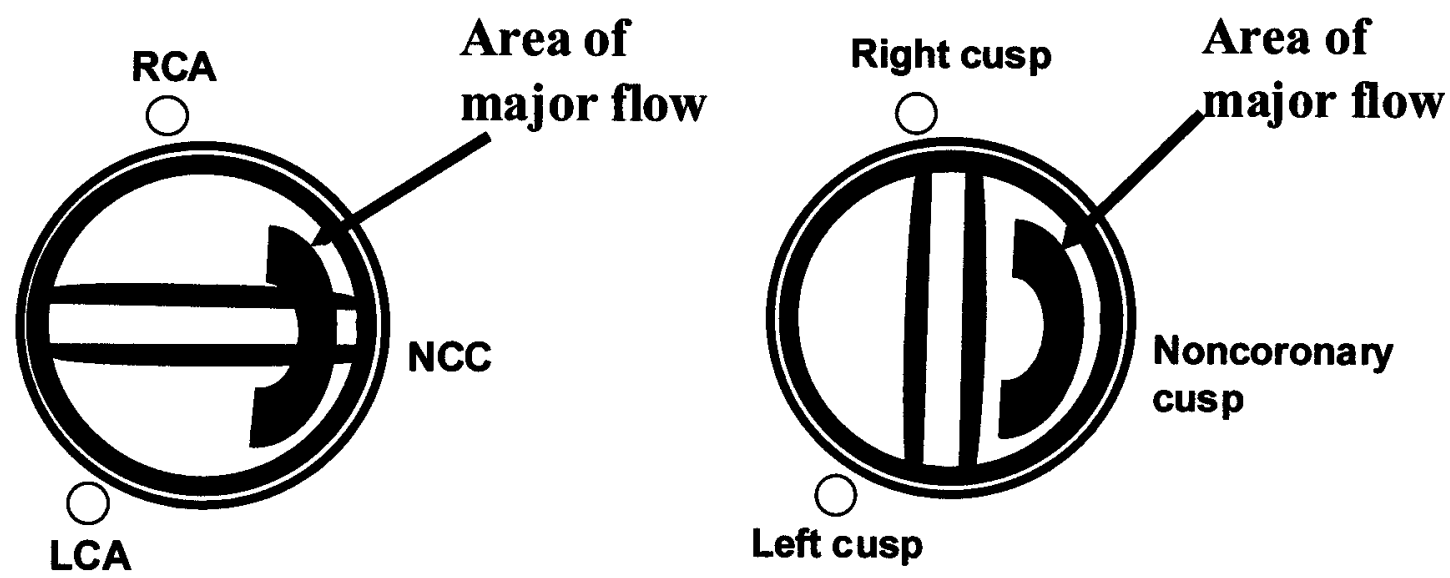

A

\section{Left cusp}

B

Figure 3. Optimum (A) and worst (B) orientation of the SJM bileaflet valve.12 Optimum hemodynamics are achieved with one orifice facing the right cusp. The area of major flow is distributed equally to the 3 openings. Rotation of $90^{\circ}$ leads to the worst orientation. RCA, Right coronary artery; NCC, noncoronary cusp; $L C A$, left coronary artery.

$4.3 \pm 0.5 \mathrm{~L} / \mathrm{min}$. After these measurements, $\mathrm{CO}$ was increased to a higher output (mean, $5.9 \pm 0.3 \mathrm{~L} / \mathrm{min}$ ). Again, stable hemodynamic conditions were achieved, with an increased heart rate of $107 \pm 11$ beats/min, a mean systolic pressure of $132 \pm 12 \mathrm{~mm} \mathrm{Hg}$, and a mean diastolic pressure of $73 \pm 13 \mathrm{~mm} \mathrm{Hg}$. There were no significant hemodynamic differences among groups.

\section{MH Tilting Disc Valve}

Preoperative LAD flow in the 4 pigs with MH valves was $24.5 \pm 4.7 \mathrm{~mL} / \mathrm{min}$. Postoperatively, LAD flow at normal $\mathrm{CO}$ and stable hemodynamic conditions, as mentioned previously, increased significantly to a mean value of $64.0 \pm$ $8.7 \mathrm{~mL} / \mathrm{min}(P<.0005)$ in the optimum position and to a mean value of $37.5 \pm 1.3 \mathrm{~mL} / \mathrm{min}(P<.005)$ in the hemodynamically worst position. The difference between the optimum and worst position was also significant $(P$ $<.0002)$. At high CO, obtained by administering adrenergic drugs and volume, as mentioned previously, these values were even higher $(115.3 \pm 19.0 \mathrm{~mL} / \mathrm{min}$ in the optimum and $73.3 \pm 23.6 \mathrm{~mL} / \mathrm{min}$ in the worst position). Again, the difference between optimal and worst orientation remained significant $(P<.05)$. Qualitative evaluation of coronary flow demonstrated a slight increase in systolic flow, but the main portion of flow remained diastolic (Figure 5). For each individual animal, the coronary flow measured in the optimum position was higher than that in the worst position. 


\section{MH}

$\mathrm{ml} / \mathrm{min}$

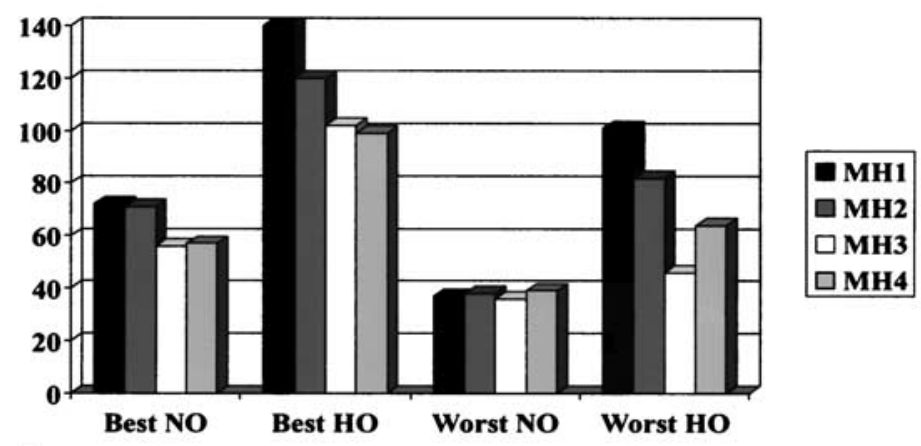

A

\section{SJM}

$\mathrm{ml} / \mathrm{min}$

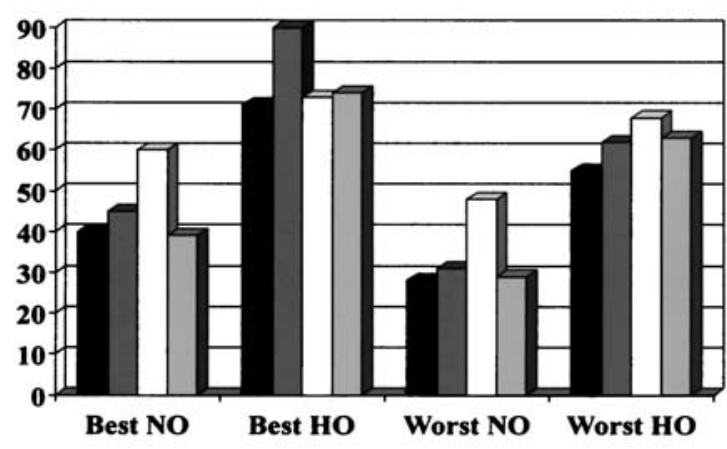

B

\section{MA}

$\mathrm{ml} / \mathrm{min}$

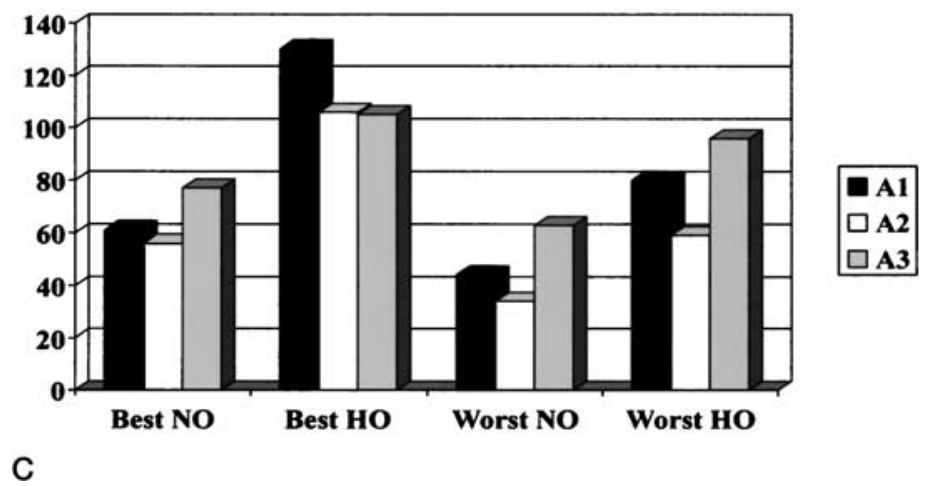

Figure 4. Coronary flow rates for the MH (A), SJM (B), and MA (C) valves. After aortic valve replacement, each individual animal demonstrated a significant increase in coronary flow from preoperative values. The highest LAD flow rates were obtained in the optimum orientation (best), whereas rotation into the worst orientation led to significantly lower flow. Increase of $\mathrm{CO}$ from normal (NO) to high $(\mathrm{HO})$ values led to a further increase of coronary flow. The valves were repeatedly rotated between the different orientations to increase reproducibility of results. 


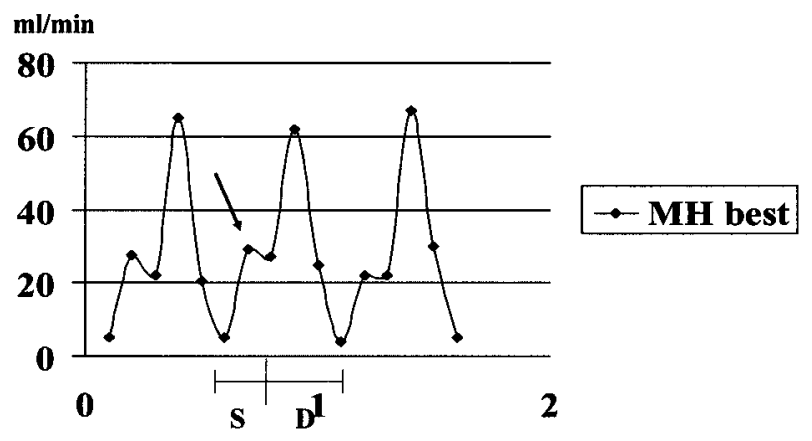

Figure 5. Qualitative measurement of the LAD coronary artery flow after aortic valve replacement with the 21-mm MH valve in the best orientation, from which peak and total coronary flow were calculated. The main portion of coronary flow remains during diastole (D), with a smaller peak during systolic (S) ejection (arrow). Similar results were obtained with other orientations and also with the SJM and MA valves.

\section{SJM Bileaflet Valve}

The preoperative LAD flow rate was $25.0 \pm 3.4 \mathrm{~mL} / \mathrm{min}$ and thus comparable with that of the animals with $\mathrm{MH}$ valves. For the SJM valves, the increase in coronary flow postoperatively at normal $\mathrm{CO}$ was statistically significant only in the optimum position, with a mean of $46.0 \pm 9.7$ $\mathrm{mL} / \mathrm{min}(P<.01)$. In the worst orientation LAD flow rate reached a mean of $34.0 \pm 9.4 \mathrm{~mL} / \mathrm{min}$, which was not significantly different from the preoperative values $(P=$ .12). For the SJM valves, the difference between the best and worst orientation was not significant. With higher $\mathrm{CO}$, these values increased to $77.0 \pm 8.8 \mathrm{~mL} / \mathrm{min}$ in the optimum and $62.0 \pm 5.3 \mathrm{~mL} / \mathrm{min}$ in the worst orientation. Again, each animal demonstrated higher coronary flow rates in the previously defined optimum position compared with those in the worst position, with no difference regarding qualitative evaluation compared with that of the $\mathrm{MH}$ or MA valves.

\section{MA Bileaflet Valve}

Preoperative LAD flow was slightly higher in the animals with MA valves $(28.3 \pm 3.8 \mathrm{~mL} / \mathrm{min})$, but this difference was not significant. The postoperative results were more comparable with those of the $\mathrm{MH}$ tilting disc valve than with those of the SJM valve. At normal CO, LAD flow increased to $64.7 \pm 11.0 \mathrm{~mL} / \mathrm{min}(P<.001)$ in the optimum and $47.0 \pm 14.7 \mathrm{~mL} / \mathrm{min}(P<.05)$ in the worst orientation. This difference between best and worst orientation was also significant $(P<.05)$. For the MA valve, a higher $\mathrm{CO}$ again led to an increase in LAD flow rates $(113.7 \pm 14.1 \mathrm{~mL} / \mathrm{min}$ in the optimum and $78.3 \pm 18.6 \mathrm{~mL} / \mathrm{min}$ in the worst orientation).

All results regarding LAD flow rates at normal and high COs for the 3 valves are summarized in Table 1.
With all 3 valves in the optimum position, the $\mathrm{MH}$ valve demonstrated no differences compared with the MA valve but significantly higher flow rates than those of the SJM valve at normal $\mathrm{CO}(P<.05)$. Comparing the 2 bileaflet valves, the MA valve showed higher LAD flow than the SJM valve at normal output $(P<.05)$. At higher output, the difference was no longer statistically significant in favor of the MA valve $(P=.16)$.

After rotation of all valves into their worst position, LAD flow rates were similar in all valve designs, with no statistical differences either at low or high CO.

\section{Discussion}

The flow profile of the aortic root is characterized by an asymmetric-eccentric flow, with the highest flow velocities along the noncoronary cusp. ${ }^{9}$ This flow distribution, as well as the anatomic characteristics (angled outflow tract and vortex formation of cardiac muscle fibers leading to a spiral ejection pattern), have not been duplicated in the majority of in vitro studies from which most information regarding hemodynamic performance of mechanical aortic valve substitutes has been obtained. Thus, in vivo studies have an increased importance in determining the expected clinical hemodynamics of aortic valves. In previous animal and clinical studies ${ }^{11-14}$ the systolic hemodynamic performance of 2 different mechanical valves (ie, the $\mathrm{MH}$ valve, representing the asymmetric tilting disc design, and the SJM valve, representing the symmetric bileaflet design) have been investigated to determine their characteristics under conditions of natural eccentric flow. For both valve types, an optimal orientation with respect to downstream turbulence and transvalvular pressure gradients has been determined. The tilting disc valve showed the best results, with its major orifice facing the noncoronary leaflet. This corresponds to results obtained earlier. ${ }^{18}$ The optimal orientation of the bileaflet valve was achieved with one of the leaflets oriented toward the right cusp. Because of its asymmetric design matching the natural eccentric flow, the MH valve guaranteed superior results in its optimum orientation compared with the SJM valve. These studies did not focus on diastolic valve performance (amount of leakage flow and closing characteristics of the different valve designs).

Diastolic function of mechanical aortic valves, focusing on the disturbed flow distribution in the sinuses of Valsalva, has not yet been intensively investigated in vivo. Thus, most information regarding the closing phase has been obtained in vitro without duplicating the physiologic flow conditions, even though some setups included a reconstruction of the sinuses. ${ }^{19}$ These studies reported a relatively large closing reflux and leakage flow across the closed SJM valve, whereas the $\mathrm{MH}$ valve has only a small closing reflux and leakage flow. ${ }^{1,2}$ The in vitro data from the MA bileaflet valve have not been published yet.

Several clinical studies have demonstrated dramatic 
TABLE 1. LAD flow of the 3 implanted valves in their optimum and worst orientation at normal versus high cardiac output

\begin{tabular}{lcrr}
\hline & MH & \multicolumn{1}{c}{ SJM } & MA \\
\hline Optimum orientation/NO (mL/min) & $64.0 \pm 8.7^{*}$ & $46.0 \pm 9.7^{*}$ & $64.7 \pm 11.0^{*}$ \\
Optimum orientation/HO (mL/min) & $115.3 \pm 19.0$ & $77 \pm 8.8$ & $113.7 \pm 14.1$ \\
Worst orientation/NO (mL/min) & $37.5 \pm 1.3$ & $34.0 \pm 9.4$ & $47.0 \pm 14.7$ \\
Worst orientation/HO (mL/min) & $73.3 \pm 23.6$ & $62.0 \pm 5.3$ & $78.3 \pm 18.6$
\end{tabular}

${ }^{*} P<.05$. NO, Normal cardiac output; $H O$, high cardiac output.

changes in coronary blood flow in patients with aortic stenosis, as well as in those with aortic regurgitation, which normalize to a certain extent after aortic valve replacement ${ }^{21,22}$ but remain pathologic under stress conditions. ${ }^{23}$ It was demonstrated that aortic valve replacement, including extracorporeal circulation and administration of cardioplegic solution, immediately leads to increased coronary flow, which persists for at least 20 hours postoperatively. ${ }^{17,24}$ This can be explained by a lower coronary artery resistance after extracorporeal circulation, which depends on the type of cardioplegic solution..$^{25}$

The present study did not focus on the effect of aortic valve replacement itself on coronary artery flow but on the role of valve orientation and design. It has been demonstrated before that valve design and orientation have an effect on turbulence downstream. ${ }^{11}$ This was observed approximately $4 \mathrm{~cm}$ downstream from the valve. We did not investigate flow in the sinuses of Valsalva, from which the coronary arteries arise, but a change in flow pattern here can be expected as a consequence of the disturbed flow further downstream.

In all 3 valves the hemodynamically optimal orientation, which was previously defined with respect to systolic parameters, such as pressure gradients or downstream turbulence, showed the highest LAD flow rates. Implantation of the $\mathrm{MH}$ valve in the optimum orientation, which was accompanied by the most physiologic flow with respect to downstream turbulence during ejection, ${ }^{11}$ now led to the highest LAD flow rates. This might be explained by a correlation between low aortic root turbulence and coronary flow rate. This is further supported by the fact that the SJM valve, which did not achieve the almost physiologic low turbulence pattern, even in the optimal orientation, demonstrated significantly lower LAD flow rates compared with those of the MH valves. The increased closing reflux and leakage flow observed in previous studies ${ }^{26}$ might further explain these results. Little information has been obtained yet for the new MA bileaflet valve because downstream turbulence in vivo has not been measured, but its larger central orifice might cause less resistance to eccentric flow, and closing volume was reported to be less than that of the SJM, which might explain the significantly increased coronary flow in the MA valve compared with in the SJM valve. Further studies are needed to investigate whether the rather moderate design changes between the 2 bileaflet valves account for the measured differences in coronary flow. The reason for the significant differences regarding LAD flow in different orientations was not determined in the present study because downstream turbulence for the MA valve has not yet been measured. It remains unclear how the coronary artery flow pattern and flow reserve influence the long-term course in the presence of a mechanical aortic valve because only the acute changes immediately after valve replacement were investigated. It has been demonstrated, in a clinical study, that coronary flow is altered in patients with mechanical aortic valve substitutes. ${ }^{24}$ This might have an effect on the late course of ventricular function after valve replacement. A clinical study focusing on valve design and orientation will be necessary to further elucidate the effect of the coronary flow alterations after valve replacement.

Rotation of the valves into their worst orientation led to a major reduction of LAD flow in all 11 implanted prostheses, eliminating any significant differences among the valves. The reduction in LAD flow was highest in the asymmetrically constructed $\mathrm{MH}$ valve and reached statistical significance. The requirement for optimum orientation of this valve design has been demonstrated before with respect to turbulence and pressure gradients. This supports the hypothesis that there is a correlation between low aortic root turbulence and high coronary flow rate. Thus, mechanical valve orientation might indirectly influence diastolic coronary artery flow, even with the valve being closed by determining the systolic disturbance of aortic root flow pattern. The advantage of the SJM in the worst orientation with respect to systolic performance, however, did not translate to a higher LAD flow rate, probably because of the increased back flow of this valve. For the SJM valve, rotation did not lead to a significant reduction of coronary artery flow, and again, the low susceptibility to rotation was observed. Although this acute study has shown higher coronary flow with the optimally orientated $\mathrm{MH}$ valve, the long-term effect of this phenomenon has not been investigated because an elevated coronary flow rate does not necessarily mean a benefit but also might indicate increased cardiac work or oxygen consumption.

The authors wish to encourage other research groups to further investigate the explanation for changes in coronary 
flow after aortic valve replacement, especially focusing on the chronic course and the clinical effect of our findings.

The present pilot study showed that mechanical valve orientation plays an important role in overall valve performance not only by influencing systolic performance of the implanted substitutes but also by significantly changing coronary flow rates during diastole.

The present study was designed to provide initial information regarding the effect of mechanical aortic valve replacement with different prostheses in different orientations. Thus, a limited number of animals were included in the study. Also, no control animals were included to evaluate the effect of cardioplegia alone on coronary artery flow. Furthermore, the study could not provide a definite answer to the question of why coronary blood flow in the closed occluder phase of the valve was affected by rotation. Further investigation of the chronic course of coronary artery flow at least 24 hours postoperatively should be performed to help answer this question.

\section{References}

1. Yoganathan AP, Woo YR, Sung HW. Turbulent shear stress measurements in the vicinity of aortic heart valve prostheses. J Biomech. 1986;19:433-42.

2. Reul H, van Son JAM, Steinseifer U, Schmitz B, Schmidt A, Schmitz $\mathrm{C}$, et al. In vitro comparison of bileaflet aortic valve prostheses. J Thorac Cardiovasc Surg. 1993;3:412-20.

3. Stein PD, Walburn FJ, Sabbah HN. Turbulent stresses in the region of aortic and pulmonary valves. J Biomech Eng. 1982;104:238-44.

4. Butchard EG, Hui-Hua L, Payne N, Buchan K, Grunkemeier GL. Twenty years' experience with the Medtronic Hall valve. J Thorac Cardiovasc Surg. 2001;121:1090-100.

5. Skoularigis J, Essop MR, Skudicky D, Middlemost SJ, Sareli P. Frequency and severity of intravascular hemolysis after left-sided cardiac valve replacement with Medtronic Hall and St. Jude Medical prostheses, and influence of prosthetic type, position, size and number. Am J Cardiol. 1993;74:587-91.

6. Hasenkam JM, Pedersen EM, Östergaard JH. Velocity fields and turbulent stresses downstream of biological and mechanical aortic valve prostheses implanted in pigs. Cardiovasc Res. 1988;22:472-83.

7. Falsetti HL, Caroll RJ, Swope RD, Chen CJ. Turbulent blood flow in the ascending aorta of dogs. Cardiovasc Res. 1983;17:529-37.

8. Nygaard H, Paulsen PK, Hasenkam JM, Pedersen EM. Turbulent shear stresses in three mechanical aortic valve prostheses in human beings. J Thorac Cardiovasc Surg. 1994;2:438-46.

9. Nygaard H, Paulsen PK, Hasenkam JM, Kromann-Hansen O, Pedersen EM, Rovsing PE. Quantitation of the turbulent shear stress distribution of normal, diseased and artificial valve prostheses in human beings. J Thorac Cardiovasc Surg. 1992;6:609-17.

10. Travis BR, Heinrich RS, Ensley AE, Gibson DE, Hashim S, Yoganathan AP. The hemodynamic effects of mechanical valve type and orientation on fluid mechanical energy loss and pressure drop in in vitro models of ventricular hypertrophy. J Heart Valve Dis. 1998;7: 345-54.

11. Kleine P, Perthel M, Nygaard H, Hansen SB, Paulsen PK, Riis C, et al. Medtronic Hall versus St. Jude Medical mechanical aortic valve: downstream turbulence with respect to rotation in pigs. $J$ Heart Valve Dis. 1998;7:548-55.

12. Kleine P, Hasenkam JM, Nygaard H, Perthel M, Wesemeyer D, Laas J. Tilting disc versus bileaflet aortic valve substitutes: intraoperative and postoperative hemodynamic performance in humans. J Heart Valve Dis. 2000;9:308-12.

13. Kleine P, Perthel M, Hasenkam JM, Nygaard H, Hansen SB, Laas J. Downstream turbulence and high intensity transient signals (HITS) following aortic valve replacement with Medtronic Hall or St. Jude Medical valve substitutes. Eur J Cardiothorac Surg. 2000;17:20-4.

14. Kleine P, Perthel M, Hasenkam JM, Nygaard H, Hansen SB, Laas J. High intensity transient signals (HITS) as parameter for optimum orientation of mechanical aortic valves. Thorac Cardiovasc Surg. 2000;48:360-3.

15. Bodnar E, Reul H, Schmitz B. Prosthetic valve function under simulated low cardiac output conditions: preliminary observations. J Heart Valve Dis. 1993;2:348-51.

16. Yoganathan AP, Chaux A, Gray RJ, Woo YR, DeRobertis M, Williams FP, et al. Bileaflet, tilting disc and porcine aortic valve substitutes: in vitro hydrodynamic characteristics. J Am Coll Cardiol. 1984; 3:313-20.

17. Jin XY, Gibson DG, Pepper JR. The effects of cardioplegia on coronary pressure-flow velocity relationships during aortic valve replacement. Eur J Cardiothorac Surg. 1999;16:324-30.

18. Olin CL, Bonfim V, Halvazulis V, Holmgren AG, Lamke BJ. Optimal insertion technique for the Björk-Shiley valve in the narrow aortic ostium. Ann Thorac Surg. 1983;36:367-76

19. Walker PG, Pedersen EM, Oyre S, Flepp L, Ringgaard S, Heinrich RS, et al. Magnetic resonance velocity imaging: a new method for prosthetic heart valve study. J Heart Valve Dis. 1995;4:296-307.

20. Sachs L. Angewandte Statistik. 8th ed. Heidelberg: Springer-Verlag; 1997. p. 345-56.

21. Hildick-Smith DJ, Shapiro LM. Coronary flow reserve improves after aortic valve replacement for aortic stenosis: an adenosine transthoracic echocardiography study. J Am Coll Cardiol. 2000;36:1889-96.

22. Tamborini G, Barbier P, Doria E, Galli C, Maltagliati A, Ossoli D, et al. Influences of aortic pressure gradient and ventricular spetal thickness with systolic coronary flow in aortic valve stenosis. Am J Cardiol. 1996;78:1303-6.

23. Takeuchi M, Nakashima Y. Effect of aortic valve replacement on coronary flow velocity during metabolic stress in a patient with aortic stenosis. Catheter Cardiovasc Diagn. 1997;40:287-90

24. Jin XY, Gibson DG, Pepper JR. The relationship of myocardial stroke work to coronary flow velocity immediately after aortic valve replacement. Ann Thorac Surg. 1999;67:705-10.

25. Kober IM, Obermayr RP, Brull T, Ehsani N, Schneider B, Spieckermann PG. Comparison of the solutions of Bretschneider, St. Thomas' Hospital and the National Institutes of Health for cardioplegic protection during moderate hypothermic arrest. Eur Surg Res. 1998;30:24351.

26. Chambers J, Fraser A, Lawford P, Nihoyannopoulos P, Simson J. Echocardiographic assessment of artificial heart valves: British society of echocardiography position paper. Br Heart J. 1994;71(suppl):6-14. 